\title{
Colistin-induced Bartter-like Syndrome: Ponder before Treatment!
}

\author{
Anju Kumari ${ }^{1} \odot$, Poonam Gupta $^{2} \odot$, Himanshu Verma $^{3} \odot$, Ajay Kumar $^{4} \odot$, Preeti Thakur ${ }^{5} \odot$, Kavish Sharma ${ }^{6} \odot$
}

\begin{abstract}
Bartter-like syndrome (BLS) is a constellation of biochemical abnormalities which include metabolic alkalosis, hypokalemia, hypocalcemia, hypomagnesemia with normal kidney function. BLS is a very rare syndrome and can be induced by certain diseases, antibiotics, diuretics, and antineoplastic drugs. Colistin is a polymicrobial bactericidal drug and currently re-emerged as the only salvation therapy against multidrug resistant bacilli especially in critically ill patients at intensive care units. Only an anecdotal case report of colistin-induced Bartter-like syndrome has been reported. We here report a case series of four critically ill patients who were on treatment with colistin and presented with serious metabolic disturbances.
\end{abstract}

Keywords: Bartter-like syndrome, Colistin, Critically ill patients.

Indian Journal of Critical Care Medicine (2022): 10.5005/jp-journals-10071-24117

\section{INTRODUCTION}

Colistimethate is a bactericidal antimicrobial and now emerged as salvage therapy with increasing incidence multidrug-resistant infections. Systemic use of colistin has been reported to cause acute kidney injury but little has been documented for its association with renal tubular salt wasting nephropathy. ${ }^{1}$

We describe series of four cases of acquired Bartter-like syndrome following the systemic administration of colistimethate.

\section{CASE 1}

A 43-year-old female was presented, who had sustained common bile duct injury during her pervious surgery for cholelithiasis. Following a revision surgery, patient was shifted to ICU with T-tube in situ. Her blood pressure was $80 / 55 \mathrm{~mm} \mathrm{Hg}$, heart rate was $130 /$ minute, and body temperature of $36.4^{\circ} \mathrm{C}$. Patient was in septic shock and was started empirically on colistin, meropenam, and targocid after obtaining all bacterial cultures. On the 12th day of colistin administration, despite daily potassium replacements, hypokalemia was persistent. ECG revealed flat T waves. Other apparent causes of potassium loss like vomiting, diarrhea, Ryle's tube, and T-tube loss were ruled out. Later, patient had also developed hypomagnesemia and hypocalcemia for which correction was started. We followed the standard hypokalemia algorithm to reach final diagnosis (Flowchart 1). A spot urinary potassium and urinary chloride were sent to differentiate between renal and extrarenal loss of potassium (Table 1). The patient had urinary potassium of $72 \mathrm{mEq} / \mathrm{L}$ confirming renal loss. Patient also had metabolic alkalosis and her urine chloride level was $111 \mathrm{mEq} / \mathrm{L}$. Nephrology consultation was done and antibiotics were pinpointed to be the underlying cause for electrolyte disturbances and a diagnosis of BLS was made. Patient was started on tablet spironolactone $50 \mathrm{mg} \mathrm{BD}$ and patient showed eu-electrolytemia after 12th day of stopping colistin.

\section{CASE 2}

A 23-year-old gentleman admitted in our ICU with Guillain-Barre syndrome. Patient's motor power was $0 / 5$ and required full
1,2,4,5 Department of Anaesthesia and Intensive Care, Safdarjung Hospital and Vardhman Mahavir Medical College, New Delhi, India

${ }^{3,6}$ Department of Nephrology, Safdarjung Hospital and Vardhman Mahavir Medical College, New Delhi, India

Corresponding Author: Ajay Kumar, Department of Anaesthesia and Intensive Care, Safdarjung Hospital and Vardhman Mahavir Medical College, New Delhi, India, Phone: +91 9871372430, e-mail: ajayk17@ gmail.com

How to cite this article: Kumari A, Gupta P, Verma H, Kumar A, Thakur P, Sharma K. Colistin-induced Bartter-like Syndrome: Ponder before Treatment! Indian J Crit Care Med 2022;26(2):239-243.

Source of support: Nil

Conflict of interest: None

mechanical ventilatory support. After 90 days of ICU stay, patient developed high-grade fever, leukocytosis, and right lower lobe consolidation. Culture of tracheal aspirate was suggestive of Acinetobacter baumanii infection sensitive only to colistin. Patient was started on parenteral colistin 9 million units (MU) loading dose followed by 3 MU 8 hourly along with meropenam $1 \mathrm{~g} 8$ hourly. After 7 days of antibiotic administration, patient had developed hypokalemia, hypomagnesemia, and metabolic alkalosis. Urinary potassium level was $58 \mathrm{mEq} / \mathrm{L}$, urinary chloride level was $108 \mathrm{mEq} / \mathrm{L}$, and urinary loss of calcium leading to a diagnosis of BLS. After 5 days of stopping therapy with colistin, patient improved spontaneously (Figs 1 and 2).

\section{CASE 3}

A 57-year-old gentleman transferred to ICU on high vasopressors, following emergency exploratory laparotomy for perforation peritonitis. Patient was empirically started on meropenam, teicoplanin, and metronidazole. His vasopressors could not be tapered off, so IV colistin was added on third postoperative day. Patient's vasopressor support was gradually tapered off and stopped on Day 7. But now he developed refractory hypokalemia, polyuria, hypomagnesemia, and hypocalcemia along with

(-) The Author(s). 2022 Open Access This article is distributed under the terms of the Creative Commons Attribution 4.0 International License (https://creativecommons. org/licenses/by-nc/4.0/), which permits unrestricted use, distribution, and non-commercial reproduction in any medium, provided you give appropriate credit to the original author(s) and the source, provide a link to the Creative Commons license, and indicate if changes were made. The Creative Commons Public Domain Dedication waiver (http://creativecommons.org/publicdomain/zero/1.0/) applies to the data made available in this article, unless otherwise stated. 
Flowchart 1: Hypokalemia algorithm

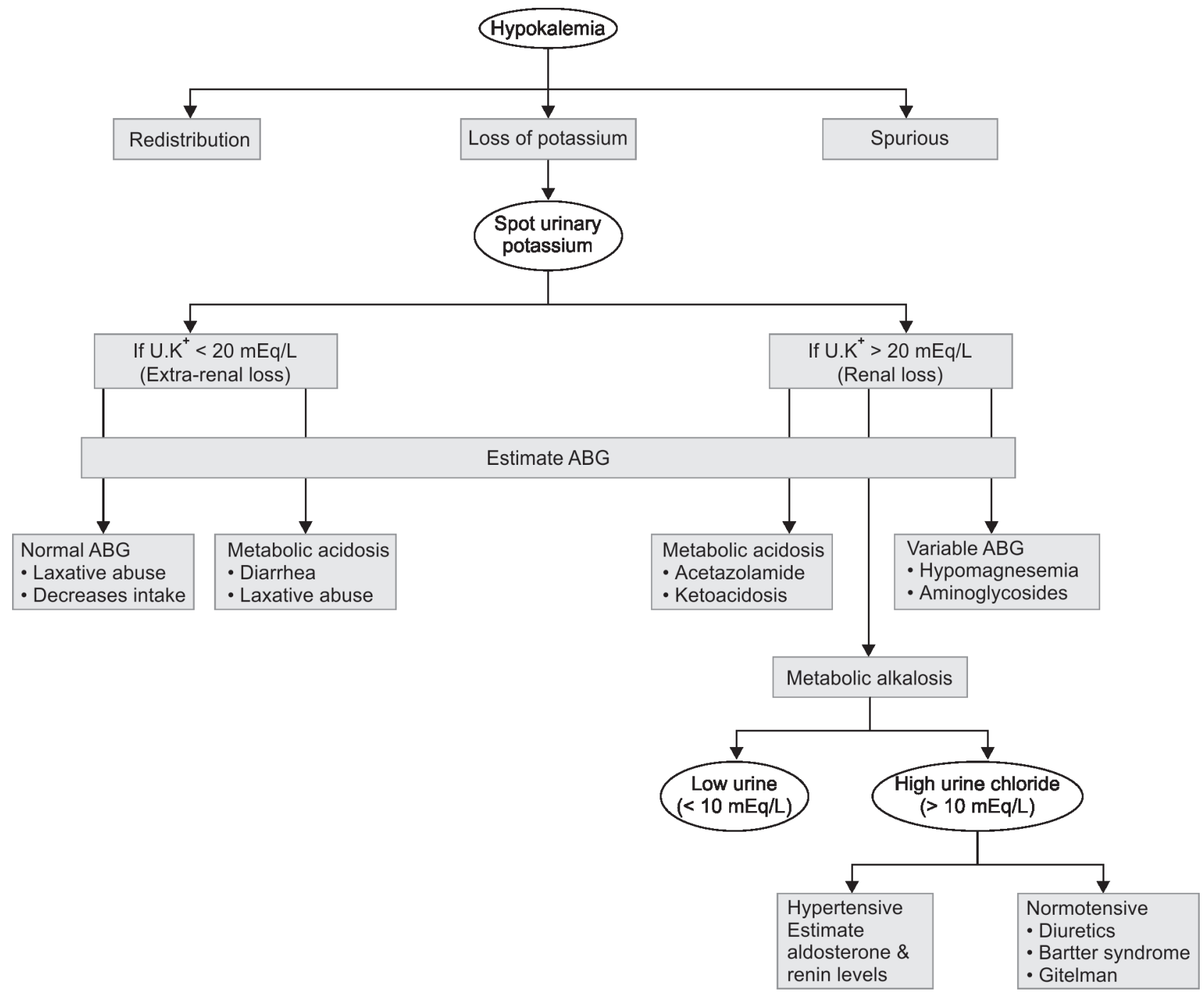

Table 1: Summary of all cases with serum and urine electrolytes along with renal function tests

\begin{tabular}{|c|c|c|c|c|}
\hline & Case 1 & Case 2 & Case 3 & Case 4 \\
\hline Sex & Female & Male & Male & Male \\
\hline Age & 43 & 23 & 57 & 50 \\
\hline Bicarbonate (mEq/L) & 30 & 33.1 & 31.9 & 31 \\
\hline $\mathrm{pH}$ & 7.5 & 7.48 & 7.52 & 7.6 \\
\hline Serum K+ (mEq/L) & 2.6 & 2.8 & 2.9 & 2.4 \\
\hline Serum $\mathrm{Mg}^{2+}(\mathrm{mg} / \mathrm{dL})$ & 0.7 & 1.1 & 0.9 & 1.1 \\
\hline Serum ionized $\mathrm{Ca}^{2+}(\mathrm{mEq} / \mathrm{L})$ & 0.9 & 0.9 & 0.8 & 0.8 \\
\hline Serum $\mathrm{Na}^{+}(\mathrm{mEq} / \mathrm{L})$ & 142 & 138 & 136 & 142 \\
\hline Serum $\mathrm{Cl}^{-}(\mathrm{mEq} / \mathrm{L})$ & 93 & 92 & 90 & 110 \\
\hline Blood urea (mg/dL) & 32 & 28 & 32 & 112 \\
\hline Serum creatinine $(\mathrm{mg} / \mathrm{dL})$ & 0.8 & 1.1 & 0.7 & $1.6-2.6$ \\
\hline Urine amount (L) & 2.0 & 1.5 & 1.8 & 1.6 \\
\hline Urine osmolality (mosmol/L) & - & - & 480 & 530 \\
\hline Urine $\mathrm{K}^{+}(\mathrm{mEq} / \mathrm{L})$ & 72 & 59.5 & 74 & 78.4 \\
\hline Urine $\mathrm{Cl}^{-}(\mathrm{mEq} / \mathrm{L})$ & 111 & 108 & 116 & 60 \\
\hline Urine $\mathrm{Ca}^{2+}(\mathrm{mg} / \mathrm{dl})$ & 5.7 & 5.63 & 5.5 & 1.87 \\
\hline Urine $\mathrm{Na}^{+}(\mathrm{mEq} / \mathrm{L})$ & 120 & 118 & 124 & 77 \\
\hline
\end{tabular}

metabolic alkalosis on seventh day of colistin administration. Electrolytes were restored after 5 days of stopping colistin (Fig. 3).

\section{Case 4}

A 50-year-old gentleman, known case of diabetes mellitus type II and benign prostatic hypertrophy developed urosepsis with acute kidney injury, and he was admitted in the medical ward. Patient was transferred to ICU, when he developed aspiration pneumonitis with ARDS. His blood pressure was $80 / 60 \mathrm{~mm} \mathrm{Hg}$, heart rate was $142 /$ minute, temperature $38.4^{\circ} \mathrm{C}, \mathrm{WBC}$ count $22,000 / \mathrm{mm}^{3}$, serum creatinine of $2.3 \mathrm{mg} / \mathrm{dL}$, and $\mathrm{HCO}_{3}{ }^{-}$of $18 \mathrm{mmol} / \mathrm{L}$. After obtaining cultures, he was started on IV antibiotics (meropenam, colistin, and linezolid after respective renal dose adjustments). Patients recovered from ARDS and IV antibiotics were gradually de-escalated. After 20 days of ICU stay, patient again developed septic shock and now blood culture was suggestive of Acinetobacter baumannii sensitive to colistin. After 8 days of treatment with IV colistin, patient had developed hypokalemia, hypomagnesemia, hypocalcemia, and metabolic alkalosis. During this period patient developed two episodes of tachyarrhythmia. After 12th day of 


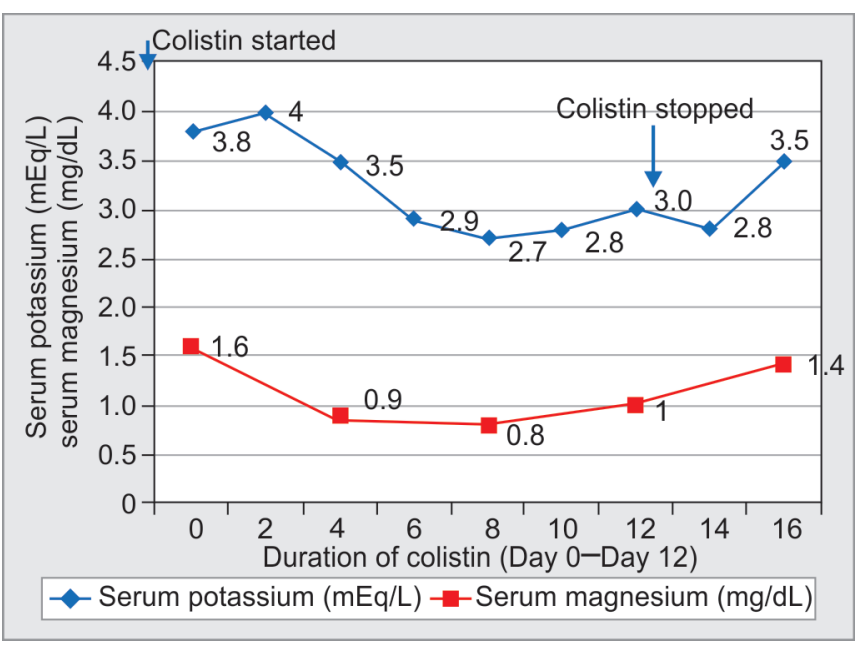

Fig. 1: Serum potassium (mEq/L) and magnesium $(\mathrm{mg} / \mathrm{dL})$ values of Case 2 on $y$-axis and shows duration of colistin therapy (in days) on $\mathrm{x}$-axis

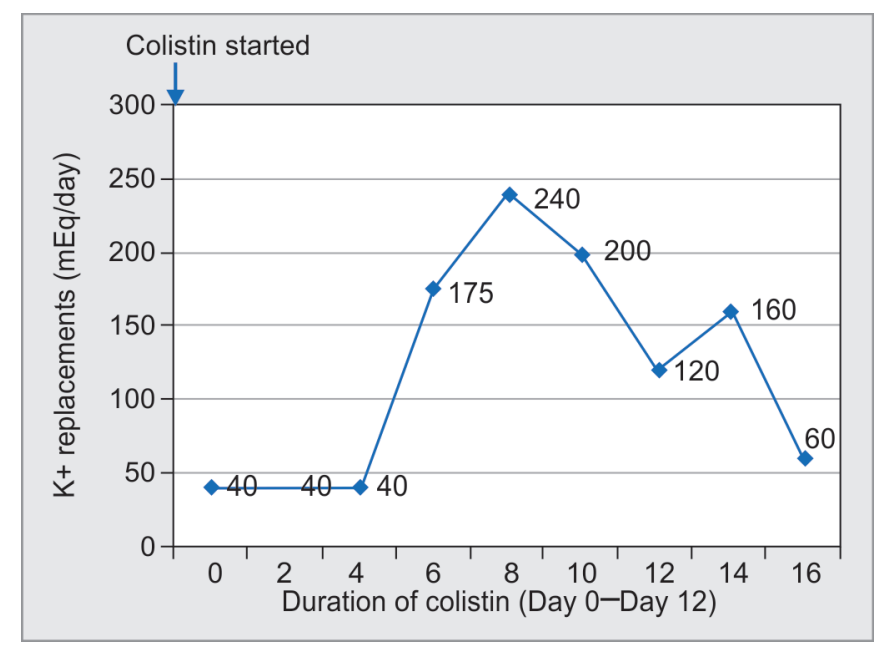

Fig. 2: Daily potassium replacement ( $\mathrm{mEq} /$ day) on $y$-axis and duration of colistin therapy (in days) on $\mathrm{x}$-axis stopping IV Colistin and adding Spironolactone (50 mg OD), electrolyte imbalances gradually improved (Tables 2 and 3).

\section{Discussion}

Bartter syndrome is an inherited disorder but its associated manifestations have been reported in various diseases like tuberculosis and as a side effect of certain drugs like amphotericin B, aminoglycosides, and colistin. This acquired form of Bartter syndrome is also called as BLS or Pseudo-Bartter syndrome. ${ }^{2}$

The first report of antibiotic-induced acquired Bartter syndrome was published in $1970{ }^{3}$ and later on, a number of authors have reported aminoglycoside-induced Bartter-like syndrome. ${ }^{4-8}$ However, there is paucity of literature on colistin-induced Bartter-like syndrome. Cakir et al. ${ }^{9}$ first reported colistin-induced acquired Bartter in a preterm infant. In 2017, the first adult case of colistin-induced BLS was reported. ${ }^{10}$ Following this, few more case reports have been published. Bartter-like metabolic abnormalities were reported to be resolved in 6-10 days following the suspension of colistin. However, some patients required addition of spironolactone. ${ }^{11,12}$

\section{Pathophysiology}

To understand the pathophysiology of Bartter syndrome, please refer to Figures 4 and 5. Apart from colistin being directly toxic to urothelium, similar to aminoglycosides, it may cause activation of the functional gain of CaSR (calcium sensing receptor) present on basolateral membrane of cells of thick ascending loop of Henle causing renal washing of sodium, potassium, calcium, and magnesium. This mechanism has been postulated to be the possible explanation of renal tubular defect ${ }^{8,13}$ (Figs 3 and 4, Table 3).

\section{Management}

The mainstay of managing Bartter-like syndrome includes correcting the volume deficit and electrolyte abnormalities, Renin Angiotensin Aldosterone system inhibitors like spironolactone and ACE-inhibitors, and nonsteroidal anti-inflammatory drugs (NSAIDs) against prostaglandin $E^{2}$ like Indomethacin, celecoxib can be a useful adjuvants. ${ }^{14}$

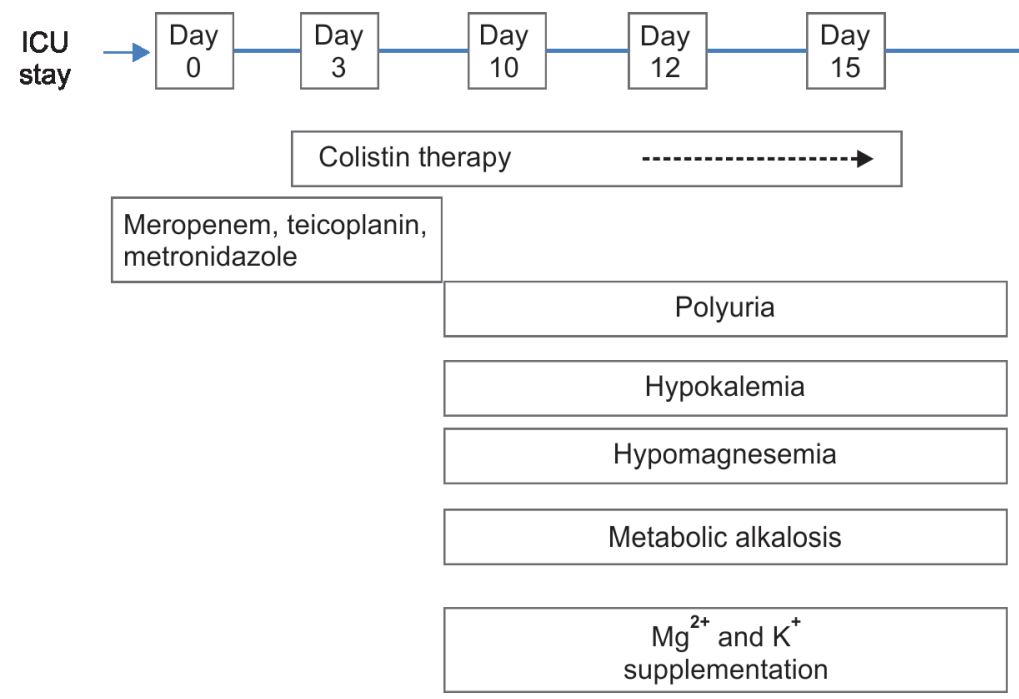

Fig. 3: Association of colistin with electrolyte disturbances and clinical symptomology 
Table 2: Dose and duration of colistin and subsequent management of all four cases

\begin{tabular}{|c|c|c|c|c|}
\hline & Case 1 & Case 2 & Case 3 & Case 4 \\
\hline Pathogen & P. aeruginosa & A. baumanii & K. pneumoniae & A. baumanii \\
\hline Site of growth & Blood & Tracheal & Blood & Blood \\
\hline Colistin dose & $3 \mathrm{MU}$ tds & $3 \mathrm{MU}$ tds & $3 \mathrm{MU}$ tds & $1 \mathrm{MU}$ tds \\
\hline $\begin{array}{l}\text { Appearance of } \\
\text { dyselectrolytemia (days) }\end{array}$ & 12 & 7 & 7 & 8 \\
\hline \multicolumn{5}{|l|}{ Management } \\
\hline Potassium (mEq/day) & 240 & 240 & 160 & 240 \\
\hline Magnesium (g/day) & 6 & 5 & 4 & 1.5 \\
\hline $\begin{array}{l}\text { Days between cessation } \\
\text { of colistin and resolution } \\
\text { of dyselectrolytemia }\end{array}$ & 12 & 4 & 5 & 12 \\
\hline Spironolactone (dose) & $50 \mathrm{mg} \mathrm{BD}$ & - & - & $50 \mathrm{mg} \mathrm{OD}$ \\
\hline
\end{tabular}

Table 3: Classification of Bartter syndrome

\begin{tabular}{ll}
\hline Types of Bartter syndrome & \multicolumn{1}{c}{ Defective gene } \\
\hline Type I (Neonatal) & Na-K $2 \mathrm{Cl}$ channel mutation \\
Type II (Neonatal) & Apical K channel mutation \\
Type III (Classic) & Basolateral Cl channel mutation \\
Type IV & Basolateral Cl channel mutation \\
(Neonatal with SNHL) & ( $\beta$ subunit) \\
Type V (Classic) & Gain of function in CaSR \\
\hline
\end{tabular}

Based on defect on any of the below mentioned channels BS has been classified into five types. Mostly BS presents in neonatal period except type $\checkmark$ which presents in adolescents and early adulthood

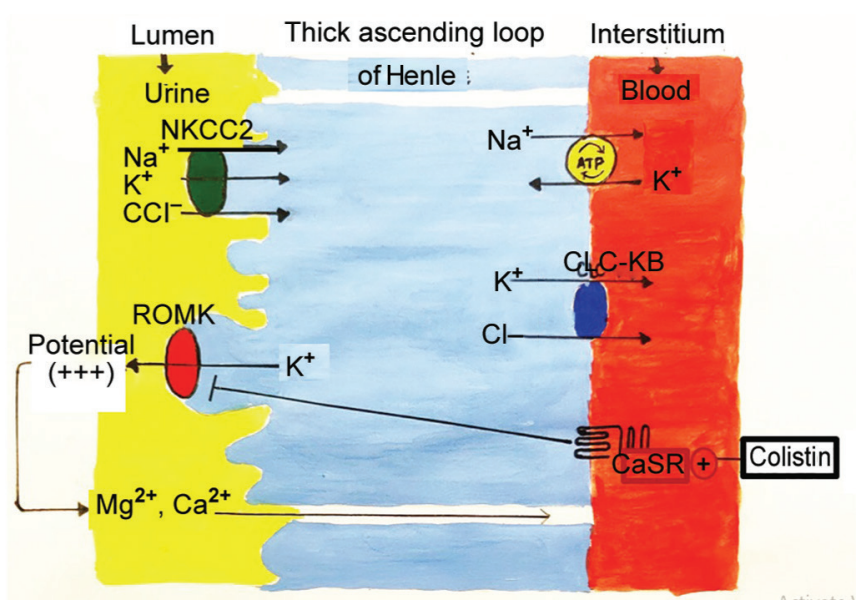

Fig. 4: Reabsorption of sodium chloride is achieved with the help of sodium potassium 2 chloride cotransporter (NKCC2). For this channel to function, concentration gradient is required across the cell which is maintained by sodium pump (sodium-potassium adenosine triphosphates), chloride channel (ClC-kb) on basolateral side, and potassium channel on luminal side (ROMK). This apical potassium channel also maintains a relatively positive voltage potential on luminal side leading to paracellular reabsorption of $\mathrm{Ca}^{2+}$ and $\mathrm{Mg}^{2+}$. Based on defect on any of these channels BS has been classified into five types (Table 3). Type $V$ is because of gain of function mutation in CaSR which normally inhibits the apical potassium channel. Gain of function leads to further inhibition of this channel, concentration gradient is lost, and thus leading to defective reabsorption of all the electrolytes. Colistin causes a similar defect in this calcium-sensing receptor
As per hospital policy, the choice of colistin was due to the emergence of multiresistant gram-negative bacilli.

In our case series, all four patients exhibited laboratory abnormalities as manifested in Bartter-like syndrome while getting treated with IV colistin. All patients were normotensive and had normal kidney function except the fourth case (Table 1). None of our patient had any apparent cause of loss of electrolytes like vomiting, diarrhea, diuretic abuse, in any of the cases. All cases had metabolic alkalosis with hypokalemia, hypomagnesemia, hypocalcemia with normal kidney functions except the fourth case. There was renal loss of potassium, chloride, and calcium in the cases except the fourth case which had only minimal changes (Table 1). Apart from serum and urinary measurement, the determination of plasma renin and serum aldosterone level could be useful in further authenticating the diagnosis; however, we failed to do so because of nonavailability of these investigations. On an average, electrolyte abnormality manifested within 7-12 days of starting therapy with colistin.

Aggressive potassium, magnesium supplementation, and dis-continuation of colistin led to resolution of electrolytes within 4-12 days of stopping IV colistin while two patients required spironolactone to treat the BLS (Table 2).

\section{Conclusion}

Bartter-like syndrome is fairly a rare complication associated with colistin. A close monitoring of serum and urine electrolytes is thus prudent and should be kept in mind while treating patients with colistin. Early diagnosis and prompt treatment can avert the risk of fatal complications. 


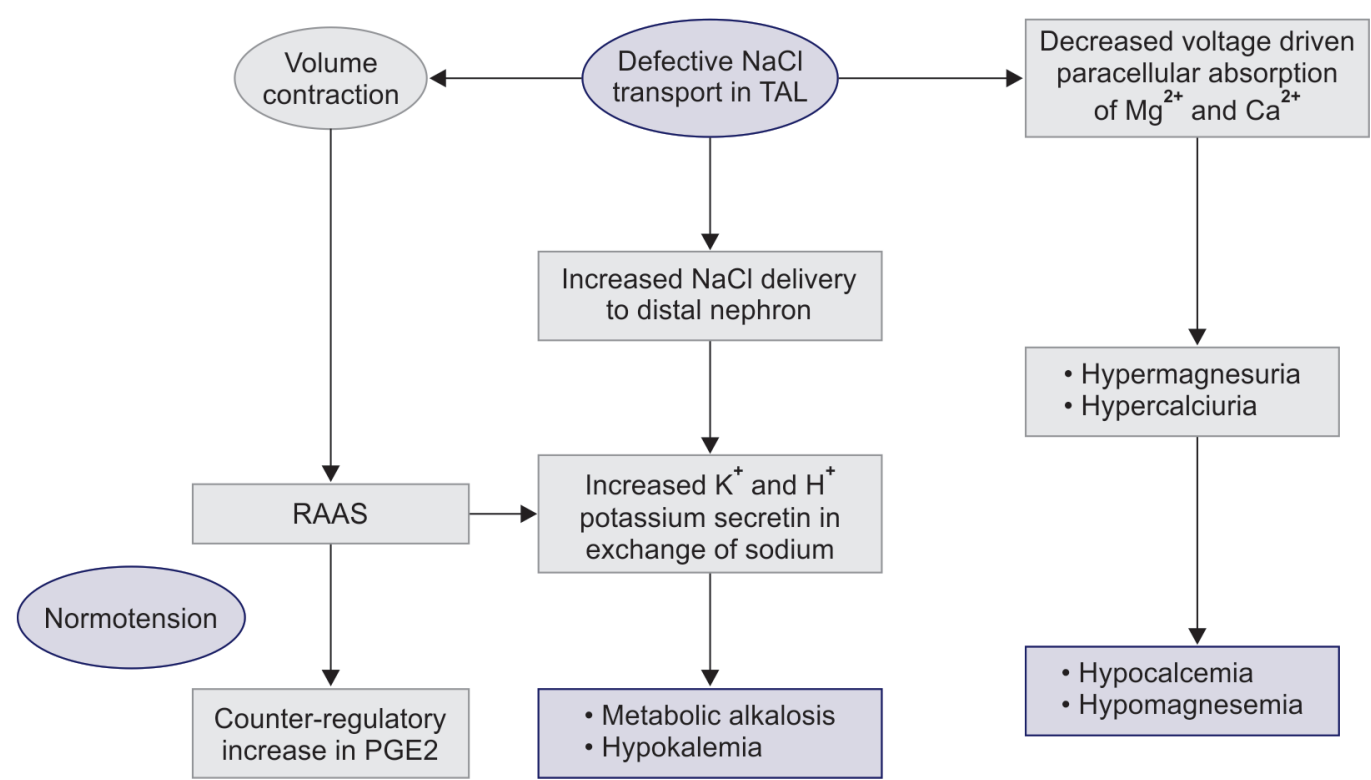

Fig. 5: The abnormal $\mathrm{NaCl}$ reabsorption in thick ascending loop of Henle results in increased delivery of $\mathrm{NaCl}$ to distal nephron. In an attempt to reabsorb sodium, potassium and hydrogen ions are lost leading to metabolic alkalosis and hypokalemia. Also excessive loss of salt and water causes activation of RAAS (Renin-angiotensin-aldosterone system) which help maintain normotension, causes counter-regulatory increase of vasodilatory PGE2, and aggravates metabolic alkalosis and hypokalemia. Defective paracellular reabsorption of calcium and magnesium leads to hypocalcemia and hypomagnesemia

\section{ORCID}

Anju Kumari $\odot$ https://orcid.org/0000-0001-7352-2799

Poonam Gupta ๑ https://orcid.org/0000-0002-3075-3412

Himanshu Verma (ㄱ https://orcid.org/0000-0002-4403-3176

Ajay Kumar (1) https://orcid.org/0000-0001-5643-7955

Preeti Thakur ㄴ https://orcid.org/0000-0001-9037-0723

Kavish Sharma ำ https://orcid.org/0000-0001-6531-106X

\section{References}

1. Spapen H, Jacobs R, Van Gorp V, Troubleyn J, Honoré PM. Renal and neurological side effects of colistin in critically ill patients. Ann Intensive Care 2011;1:14. DOI: 10.1186/2110-5820-1-14.

2. Lee $B H$, Cho Hy, Lee H, Han KH, Kang HG, Ha IS, et al. Genetic basis of Barter syndrome in Korea. Nehrol Dial Transplant 2012;27(4); 1516-1521. DOI: 10.1093/ndt/gfr475.

3. Holmes AM, Hesling CM, Wilson TM. Drug-induced secondary hyperaldosteronism in patients with pulmonary tuberculosis. Q J Med 1970;39:299-315. PMID: 5449594.

4. Kelnar CJ, Taor WS, Reynolds DJ, Smith DR, Slavin BM, Brook CG. Hypomagnesaemic hypocalcaemia with hypokalemia caused by treatment with high dose gentamicin. Arch Dis Child 1978;53(10): 817-820. DOI: 10.1136/adc.53.10.817.

5. Keating MJ, Sethi MR, Bodey GP, Samaan NA. Hypocalcemia with hypoparathyroidism and renal tubular dysfunction associated with aminoglycoside therapy. Cancer 1977;39(4):1410-1414. DOI: 10.1002/1097-0142(197704)39:4<1410::aid-cncr2820390409> 3.0.co;2-d.
6. Alexandridis G, Liberopoulos E, Elisaf M. Aminoglycoside-induced reversible tubular dysfunction. Pharmacology 2003;67(3):118-120. DOI : 10.1159/000067797.

7. Chrispal A, Boorugu H, Prabhakar AT, Moses V. Amikacin-induced type 5 Bartter-like syndrome with severe hypocalcemia. J Postgrad Med 2009;55(3): 208-210. DOI : 10.4103/0022-3859.57407.

8. Chou CL, Hwang Y, Chau T, Lin SH. Acquired Bartter-like syndrome associated with gentamicin administration. Am J Med Sci 2005;329(3):144-149. DOI: :10.1097/00000441-200503000-00007.

9. Cakir U, Alan S, Zeybek C, Erdeve O, Atasay B, Yalcinkaya F, et al. Acquired Bartter-like syndrome associated with colistin use in a preterm infant. Ren Fail 2013;35(3):411-413. DOI:10.3109/08860 22X.2012.761084.

10. Eldin TK, Tosone G, Capuano A, Orlando R. Reversible hypokalemia and Bartter-like syndrome during prolonged systemic therapy with colistimethate sodium in an adult patient. Drug Saf Case Rep 2017;4(1):10. DOI: 10.1007/s40800-017-0052-1.

11. Choks T, Shah S. Prolonged intravenous colistin use associated with acquired Bartter-like syndrome in an adult patient: a case report. EMJ Nephrol 2018;6(1):102-105.

12. Ruiz Acosta AG, Acuna Diaz AV, Labrano Elias MME, Valenzuela Vazquez CA. Pseudo Bartter syndrome associated with intravenous infusion of colistin. Rev Virtual Soc Parag Med Int 2018;5(2): 79-84. DOI: 10.18004/rvspmi/2312-3893/2018.05(02)79-084.

13. Desfleurs E, Wittner M, Simeone S, Pajaud S, Moine G, Rajerison R, et al. Calcium-sensing receptor: regulation of electrolyte transport in the thick ascending limb of Henle's loop. Kidney Blood Press Res 1998;21(6):401-412. DOI: 10.1159/000025892.

14. Breazu CM, Bartos A, Bartos D. Bartter and Gitelman syndromes. In: Fluid and electrolyte disorders 2018. DOI: 10.5772/intechopen.81745. 